\title{
A IMAGEM DIGITAL COMO DISPOSITIVO DE APROPRIAÇÃO DOS MODOS DE SUBJETIVAÇÃO CONTEMPORÂNEOS
}

\author{
Patrícia Beatriz Argôllo Gomes Kirst* \\ Tania Mara Galli Fonseca*
}

\begin{abstract}
RESUMO. O artigo "A imagem digital como dispositivo de apropriação dos modos de subjetivação contemporâneos" trata de problematizar a imagem digital como emblema dos atuais modos de produção de subjetividade. Na imagem digital, o tempo é resignificado na despotencialização de seus aspectos acumulativos vindo a ser integrado a uma temporalidade transitória e de confluência de encontros. A discussão proposta expõe dimensões do conceito de virtual afirmando-o como potência imaginativa, fruto de agenciamentos múltiplos e heterogêneos entre arte, tecnologia e ciência fundando novas interações entre sujeito e mundo. É justamente, desde uma leitura da realidade como pura transformação, não existindo essências e sim estados de coisas, que a simulação se torna adequada para pensar as relações entre imagem digital e subjetividade.
\end{abstract}

Palavras-chave: Imagem digital; contemporaneidade; subjetivação.

\section{THE DIGITAL IMAGE AS A TOOL FOR THE ASSUMPTION OF CONTEMPORARY SUBJECTIVIZING METHODS}

\begin{abstract}
The article "The digital image as a tool for the assumption of contemporary subjectivizing methods" brings into the matter the digital image as the symbol of the current ways we produce subjectivity. In the digital image, time is redefined in the weakness of its accumulative aspects eventually integrated to a momentary temporality and of confluence of meetings. The proposed discussion exposes dimensions of the concept of virtuality strengthning it as an imaginative power, creation of multiple and heterogeneous administrations among art, technology and science establishing new interactions between man and world. Since reality is seen as pure transformation, without the existence of essences and yet the state of things, simulation becomes appropriate to the thinking of the relationship between digital image and subjectivity.
\end{abstract}

Key words: Digital image; contemporarity; subjectivity..

\section{"LA IMAGEN DIGITAL COMO DISPOSITIVO DE APROPIACIÓN DE LOS MODOS DE SUBJETIVIDAD CONTEMPORÁNEOS"}

RESUMEN. El artículo "La imagen digital como dispositivo de apropiación de los modos de subjetividad contemporáneos" trata de problematizar la imagen digital como emblema de los actuales modo de producción de subjetividad. En la imagen digital, el tiempo es otra vez significado en la pérdida de potencia de sus aspectos acumulativos siendo integrado a una temporalidad transitoria y de confluencia de encuentros. La discusión propuesta expone dimensiones del concepto de virtual afirmándolo como potencia imaginativa, fruto de agenciamentos múltiplos y heterogéneos entre arte, tecnología y ciencia fundando nuevas interacciones entre sujeto y mundo. Es justamente, desde una lectura de la realidad como pura transformación, no existiendo esencias y sí estados de cosas que la simulación se torna adecuada para pensar las relaciones entre imagen digital y subjetividad.

Palabras-clave: Imagen digital; contemporaneidad; subjetividad.

Uma boa imagem mental para relacionar a imagem digital e a produção de subjetividade é a de uma flor que se faz pingo e este pingo virando estrela e em estrelas transformam-se os olhos do espectador.

Psicóloga. Doutoranda do Programa de Pós-Graduação em Informática na Educação da Universidade Federal do Rio Grande do Sul (PPGIE/UFRGS), Brasil.

\# Psicóloga. Doutora em Educação. Pós-doutora. Professora titular da UFRGS nos Programas de Pós-Graduação em Psicologia Social e Institucional (PPGPSI) e Informática na Educação (PPGIE), Brasil. 
Assim, um se faz no outro e quem vê tem o corpo tornado imagem. É destas possibilidades de acoplamento, dos jogos das imagens pregnantes, imagens autopoiéticas, imagens em corpos e corpos em imagens que queremos pensar os modos de subjetivação contemporâneos.

A imagem desde sempre apresentou um mistério ligado ao esforço de decifrar e tornar possível. Dar sentido ao mundo, oferecendo-se como espelho, certamente, imperfeito. As tantas miragens do mundo que vêm desde as pinturas nas cavernas, passando da pintura, a fotografia, à televisão e sua aldeia global e, mais recentemente, à imagem digital, dizem das transformações dos modos de pensar e arcar com os impasses da processualidade do real/sujeito.

Mais precisamente, trata-se da localização das tantas formas de relação com o real através de que o sujeito se inventa através dos tempos. Estas tecnologias de apreensão explicitam o limite do pensamento e da capacidade de criação de mundos e subjetividade.

O que foi modificado na imagem, através de sua digitalização no contemporâneo, basicamente, é a sua relação com a verdade e sua potência virtual. $\mathrm{Na}$ imagem digitalizada, a simulação adquire o atributo de infinita, a imagem depoimento do mundo vira imagem-imaginação. O real se reinaugura através de um click no mouse. O tempo linear e cumulativo das verdades infinitas, das imagens como duplicidade podendo provar algo, é substituído por um tempo fugidio, sempre em trânsito, tempo do encontro que acompanha o acender da faísca criativa.

$\mathrm{O}$ virtual, neste sentido, deve ser problematizado, pois está o tempo todo sendo movimentado pelo trânsito de atualizações decorrentes do trabalho na imagem digital. Mas, quais podem ser as vias conceituais para pensarmos a arquitetura do virtual, não o concebendo como somente da ordem da tecnologia?

Entraremos no terreno do virtual e seus três conceitos-chave que segundo André Parente (1999), podem ser pensados, em primeiro lugar, através da idéia de que, na cultura contemporânea a imagem se tornou auto-referente quebrando com os modelos de representação, em autores como Arlindo Machado, Edmond Couchot e Paul Fargier; em segundo, temos uma tendência mais pessimista onde a imagem virtual é um significante sem referente social, em autores como Virilio e Baudrillard e, finalmente, existe a afirmação de autores como Gilles Deleuze, Félix Guattari e Pierre Lévy de que o virtual é potência imaginativa, fruto de agenciamentos múltiplos e heterogêneos entre arte, tecnologia e ciência fundando novas interações entre sujeito e mundo.

É a partir desta terceira tendência de compreensão da imagem, com sua potência virtual, que nortearemos nossa escrita. A imagem digital como espaço de criação de mundos e rompimento com a perspectiva de duplicidade signo-real inovando a sensibilidade em relação ao tempo e tratando as potências virtuais aí contidas como emblema do desejo de trânsito de informações resignificadas conforme a demanda do momento; emblema da modelagem própria de nossos tempos e de suas formas de conhecer. Se toda a imagem é linguagem, temos, na imagem digital, um acesso ao ritmo e à estética da produção de subjetividade contemporânea.

Então, não é possível separar o mundo da imagem, o real da imagem, o corpo da imagem, pois tudo é tentativa de construção de sentido. A leitura e criação da imagem digital colocam em jogo a formação do olhar ou, mais exatamente, como se produz subjetividade e isto se dá através da memória como mar de imagens pronto a ser cartografado pelo presente, memória como espaço virtual capturado pela última vista.

Nem passado, nem futuro, inexoravelmente o agora é que nos defronta. O passado pode vir, mas sempre atravessado pela última cena. Quanto ao futuro, simplesmente não existe, é somente imagem. Vemos com o visto. Dobramos com a própria dobra. A captura da imagem é da mesma ordem da lembrança, ao lembrarmos estamos criando e decifrando o próprio corpo.

Não se pode, portanto, aprender com a imagem. Podemos modificá-la para fusionar com o passado, o aqui e agora. Então, a imagem convida à diferença, pois, potencialmente, guarda outros muitos regimes de visão. A imagem é violenta no sentido que não possui sua própria decifração, mas se sincroniza com a memória passando a exigir seu desdobramento nela própria.

Assim, a violência da imagem repousa, muito frequientemente, onde a imagem pode projetar um reflexo, tornando-se um pequeno espelho. É, em pelo menos, um ponto de acoplamento entre o espectador e imagem que o sujeito se surpreende com o reflexo de seus próprios olhos. Se não houver pelo menos um ponto onde o sujeito se descubra, a imagem é refutada, procura-se um novo link. A imagem pode ser vista e não ser subjetivada e o que está em pauta é a própria persuasão-conjuntura onde o inconsciente pode ser seduzido então entregando-se a mais uma tradução. Por isto, a imagem não é em si, é para e com o sujeito, existe na relação. 
Pensar a subjetividade através da imagem permite pensar o mundo como superfície movimentada e o sujeito como dobra desta superfície/mundo. Talvez, o mais intrigante é como o sujeito se produz frente ao mundo, frente a tantas imagens, como encontra lugar para acomodar a si? Pensadores como Michel Foucault, Michel Serres e Gilles Deleuze produziram boa parte da dobra de suas obras tentando arcar com este enigma.

Segundo Deleuze (1992, p. 195), o conceito de dobra-inflexão está ligado à singularidade, textura, diferença/potência de metamorfose, pois "o mundo está dobrado em cada alma”, mas conforme cenas e tempo específicos para aquele sujeito. Pode-se pensar na dobra com base em Michel Serres (1994, p. 51), que a traduz como implicação no mundo, ou dobra como "pli" de explicação, multiplicação, complicação, onde o sujeito se movimenta no sentido de dar conta de algo, "a dobragem forma a direção do pequeno no grande, a dobra permite passar do lugar ao espaço", seria o ser cavando a si mesmo do mundo. E ainda para Foucault (citado por Deleuze, 1991, p. 113-114) a dobra é concebida como espessura do fora-mundo recolhida em si, interior do exterior. Sendo o exterior o próprio tempo, o sujeito ao ser arrastado nele, forma memória ("o tempo como sujeito chama-se memória"), esta não só de si, meramente psicológica, mas memória de mundo, "memória esquecida". O exterior também é tido como força e o sujeito-dobra como resistência/seleção a tudo o que pode/poderia arrastar os processos de feitura de si/ eterno vir a ser. Além de tempo e da força, o fora foi pensado como o impensado e a dobra como pensamento ou espaço de subjetivação, "pois não se pode descobrir o impensado (...) sem prontamente aproximá-lo de si”. (Deleuze, 1991, p. 126).

Enfim, a existência do ser está dentro das entranhas do mundo, ou, ainda poderíamos pensar no fora ou no tempo como plano de virtualidade e a existência como canal de sua atualização. Existir ou subjetivar o mundo é atualizar. No campo infinito das diferenças das existências, a complexidade está ligada à dobra, no sentido de quanto mais especializações possui o ser, mais dobras com especializações e finalidades. Como um corpo com seus órgãos ou um software com seus comandos, ou mesmo a imagem digital com seus subsistemas e camadas de agregação em píxels. Assim, cada dobra ou órgão é entendido como um subsistema, não se configurando como ponto em relação com outro ponto em um esquema linear, mas em multiplicidade dobrada em muitas variações.
Ainda poderemos pensar que, conforme a demanda de função de uma dobra, ela irá redobrar-se e ativar outras dobras que darão a ela própria e as outras formas diversas conforme a necessidade de atividade. Tal atividade pode ser acionada por imprevistos, por novidades, como quando um corpo é tomado por um vírus ou quando uma máquina entra em pane ou, ainda, quando um sujeito sente-se convocado a mergulhar em uma experiência não vivida e a matéria e a subjetividade entram em tipo de curvatura trans ou sem a certeza de onde irão parar. Pelas forças do fora é que a dobra redobra-se ao infinito, pois um corpo, para manter-se, deve adaptar-se aos acontecimentos. A curvatura da dobra é sempre transversal, pois a subjetividade nunca é vetorizada por um só ente de cada vez, mas por uma série de entes demandantes de ajustes maiores ou menores que fazem o corpopensamento oscilar em novas emergências. Mesmo que, o ser fosse acionado por apenas um ente, este é composto por molecularidades que o fragmentam infinitamente, compondo campos de força e, portanto, campos de curvatura diferentes.

A coisa, o objeto, o sujeito, o ser, a multidão, o referente não são um, são multiplicidade dobrada e redobrada na divisão ilimitada de cada matéria com suas propriedades de diferenciação e exposição. Estas propriedades produzem os corpos em dureza, molaridade e resistência e, simultaneamente, em fluidez, criação e molecularidades. A força de fluidez dos corpos, suas adaptações, marcam sua expressão de curvatura em relação às suas exposições às forças que dobram e pressionam em direção às formas. Sendo assim, as formas são convocadas pela compressão das forças. A menor unidade de um ser é ainda uma dobra, pois poderá diferenciar-se na relação com as forças ou com outras dobras.

Em relação à fotografia digital em processo, poderíamos pensar o píxel não mais como ponto, mas como dobra infinetesimal da imagem. Então, a organização não se dá entre partes, mas em um infinito de dobras que em seu movimento de des-re-dobragem, formam novos sistemas de agregação. Tal processo organizativo apresenta-se na forma conservando a força que, convocada por outra força, destruirá a forma anterior. A desdobra é nova dobra. Na relação entre transfotografia e subjetivação, sujeito e imagem digital, multidão e tecnologia o que marca a diferença é a força, pois segundo Deleuze (1991, p. 19) “a matéria orgânica não é o contrário da inorgânica. Inorgânica ou orgânica é a mesma matéria, mas não são as mesmas forças ativas que se exercem sobre ela." A relação de forças possui imanência com o movimento variável, pois, o espaço que os corpos 
ocupam não poderá ser o mesmo; assim, as dobras do encontro são únicas e geram novos espaços, novas ocupações territoriais. Os processos de des-redobragem, a partir dos espaços de habitação dos píxels na imagem, dos sujeitos no mundo e, a cada deslocamento, gerado pelas curvaturas resultantes das forças vão inaugurando novos espaços. Cada deslocamento gerado pelas forças geradoras dos encontros, refazem o cenário da vida. $\mathrm{A}$ transfotografia, por sua gênese digital e, portanto, de movimento e efemeridade, é um meio por onde se diferencia outras espécies de organismos ou organizações. Os pixels em troca espacial produzem um viveiro de alteração do pensamento e das sensibilidades: subjetivação.

Os movimentos que a transfotografia recebe da multidão são os princípios imateriais de sua vida singular. O lugar, o espaço que a imagem digital ocupa indica sua subjetivação, as suas companhias, seus parceiros humanos e inumanos em diferenciação mútua. Sua morada no software e nos corpos que a inventam.

Seguindo os conceitos expostos, a própria superfície suporta, então, o que se pode chamar de "interioridade" do sujeito no instante, a parte externa da dobra, aquela que toca o fora e que pode ser explorada com o olhar. Mas, a camada fronteiriça está colada às mais interiores em "continuum" e, por isto, "traz a pista" daquilo que a faz emergir.

Os olhos são fundadores/dobradores do mundo, sendo através deles que, em primeiro lugar, somos tomados por sua materialidade. Canais fundamentais de apropriação do fora, sendo chamados por alguns de "janelas da alma", sugerindo, talvez, que a visão pode ser uma das pontas da dobra.

Em uma ponta, a percepção com suas deformações, defesas, sua filtragem, sua influência, sua memória e, de outro, o mundo dos perceptos que, por mais que se queira fechar os olhos, adentra todas as janelas do corpo, influindo e tornando-se subjetividade. A subjetividade é imagética na medida em que, de sua metamorfose, revela, declara, conhece e deixa entrar, dobrando mundos... Pode-se perguntar: $\mathrm{O}$ que o sujeito pode ser diante de uma imagem? Ou como cada um vai incorporar/ser possuído pelo mundo através da velocidade mutante da imagem digital?

A dobra, gerada pelo artifício imagético digital, é a retenção da passagem de algum aspecto do mundo que implica a sobre-vida de um momento e sua proliferação de entretempos.

O que está presente nesta ficção que sempre está com seu outro pronto para tomar seu lugar? Acreditamos ser justamente a idéia de que não existe a palavra final, não existe a certeza, não há porto para o pensamento. O que resta para o sujeito contemporâneo é a manutenção constante da narrativa no sentido de não deixar o labirinto hipertextual fazer calar, pois a vivacidade da narrativa da imagem constante e deslocada de si aponta para um mundo em aberto e ainda por fazer.

$\mathrm{E}$, esta idéia se opõe à idéia de que a imagem digital indica uma fabulação que não se interessa mais pelo referente e que não mantém laço nenhum com o social. Opõe-se ainda, à idéia de por ter-se à disposição imagens mutantes em abundância, acabam as potências de resistência. É preciso perder o medo de navegar resignificando o virtual e as distâncias, concebendo que virtual é tudo o que não é aqui/agora estando lá fora e, não ligado unicamente, às possibilidades que as ferramentas de simulação nos trazem.

O que está em questão é entender o sujeito não como cópia de si mesmo, mas como entidade em estado de outramento não conforme sua vontade ou sua pseudo-liberdade, mas pelas ofertas externas, pelo horizonte, que será, em alguma medida, alvo do desejo: medida de singularidade. Então, a imagem digital pode ser emblema de um estado de outramento que, consiste em tornar-se estrangeiro de si mesmo, possibilitando ao sujeito experimentar-se em novos espaços e modos de existência. Aqui, o sujeito pode ser entendido, como uma multiplicidade à espera de recursos para sair do conhecido e refazer sua forma através dos devires apresentados pelo mundo.

O desejo é movido pela necessidade de atualização e não pela vontade de satisfação. Enfim, traduzir é duplicar-se não em outro idêntico, mas em um outro efêmero. Somos o corpo do mundo em ação. Se o sujeito busca deslocar-se de si para manter a própria vida, a imagem não pode caber dentro da representação do Fora, pois isto remeteria à noção de um sujeito identitário e impedido do encontro com a diferença. A imagem vista como motor da representação está fadada a aprisionar a diferença dentro da noção da semelhança, do ponto de vista da percepção e da analogia, do ponto de vista do juízo.

Tal complexificação sugere conceitos porosos e, por vezes, voláteis e, em se tratando da velocidade da imagem digital, o sujeito contemporâneo está frente a frente com sua alteridade, interminavelmente. O que está emergindo é a nova gestão do conhecimento que convoca novas formas de conceber a autoria quebrando a hierarquia capitalística dos espaçostempo e criando um espaço polissêmico para a atribuição dos sentidos de si. O sujeito não irá, definitivamente, dar conta do mar de imagens, 
entretanto poderá descobrir respostas sem solução prédeterminada e eliminar o "correto" e orientar para a noção daquilo que pode ou não fazer sentido.

Nesta quebra de hierarquia, o pensamento grego que originou, até então, as formas de conceber o conhecimento entra em crise. Mas o que concede a visão? Ou melhor, o que a imagem pode oferecer na apreensão do real e no aprendizado da vida? Retomando, de forma sucinta, o pensamento grego, para Platão a imagem integra o terreno das ilusões e suas potências tomam força no convencimento do espectador menos atento. Neste sentido, a imagem desfigura e fragmenta a forma primeira, ideal, e, por assim dizer "verdadeira". Aristóteles concebe a imagem como parte importante e privilegiada do aprendizado sobre o mundo. É preciso "imitar" para aprender o mundo.

Nessa discussão, está presente, em ambos, talvez de forma indireta, a resistência ao devir, pois o que importa é que a imagem seja ou possibilite a verdade ou a aprendizagem da realidade sem distorções. Entretanto, pode-se admitir uma terceira possibilidade: pensar a simulação como verdade, a imagem como expressão da vida, em constante reconfiguração pelos olhos do espectador, sempre trocando de "aparência".

É justamente desde uma leitura da realidade como pura transformação, não existindo essências e sim estados de coisas, que a simulação se torna adequada para pensar as relações entre imagem e subjetividade. Na vida, o terreno é acidentado, tenso e mutante e, a simulação não só é marca, é o caminho dos movimentos do desejo para a leitura de signos. $\mathrm{O}$ desejo é o alquimista da imagem em imagem tornando possível a articulação das diferentes fluências da linguagem. $\mathrm{O}$ desejo promove um ente mestiço, não dicotômico, que nasce nas derivas da imagem sem fim.

Félix Guattari e Suely Rolnik (1993) afirmam que a simulação é a exteriorização do desejo, cuja intensidade toma uma forma provisória, mas consistente, em matéria e expressão. A forma ideal não existe, o rosto tampouco, a não ser que seja considerado uma sucessão de máscaras. A simulação nada tem a ver com falsidade ou fingimento; é, apenas, uma condutora da intensidade dos afetos, tornando-se, então, realidade. A realidade é artifício e, neste sentido, a busca pela verdade se torna um falso problema.

"Vê-se que é no artifício e só nele que as intensidades ganham e perdem sentido, produzindo-se mundos e desmanchando-se outros, tudo ao mesmo tempo. Movimentos de territorialização: intensidades aterrizando em certas matérias de expressão; nascimento de mundos" (Guattari \& Rolnik, 1993, p. 23).

A imagem pode ser uma das inúmeras formas que o sujeito emprega para simular(se), expressando-se através da escolha de certos "portos" dentro do "mar" da linguagem. Então, a imagem digital, pensada como multiplicidade de signos, simulação do mundo ou como "tempo redescoberto" (Proust, 1998), é criação e, portanto, nada mais é do que um território possível para o trânsito da perpétua busca/fuga das tantas formas do desejo e do tempo.

A imagem coloca em questão que, mesmo nos tempos de fotografia analógica, que carregava a certeza da prova e da presença, portanto, no lugar da cena, esta era desfigurada e recriada pela memória do espectador. A fotografia analógica, por exemplo, por estas propriedades, nos transportava para um passado habitado pelo produtor da imagem. E, em contrapartida, a imagem digital faz com que possamos marcá-la com qualquer tempo fugindo da tríade passado, presente, futuro sendo marcada pelo tempo momentâneo.

Podemos temporalizar a imagem digital, fazê-la carregar diversos regimes do tempo, pois ao mesmo tempo, em que se transforma carrega a memória de suas faces anteriores, tendo no píxel, uma espécie de "célula tronco" ou grão da matéria do mundo que, quando reaplicado, pode gerar qualquer geografia de qualquer paisagem, contendo, no caso da imagem, tempo históricos, artísticos, tecnológicos, científicos... A imagem digital está sempre pronta à auto-destruir-se para renovar sua cena, escapando até do tempo e de suas misérias, pois está, de alguma forma, "forever young”.

Alguns fotógrafos melancólicos dizem, carregando suas velhas máquinas analógicas que não se adaptam à imagem digital porque estas não têm alma, indicando uma outra incidência temporal que não remete aquele passado-porto que ostentava a habitação da cena com o corpo físico estando "olhono-olho" com o referente. A seqüencialidade histórica foi rompida, pode-se entrar na cena, virtualmente, sem sujar os sapatos.

Sabe-se que a imagem não é transparente. Algo se interpõe entre a mensagem e seu tradutor, não havendo possibilidade de input e output sem que, nesta seqüência, não se leve em conta o híbrido com o nascimento de uma terceira imagem composta pela existência daquele que vê. Aquilo que, anteriormente, poder-se-ia chamar de descrição, narrativa ou discurso, a partir deste ponto de vista, pode ser chamado de produção existencial ou cartografia do tempo. 
O olhar nunca foi passivo. A imagem não vem somente de fora e, certamente, o grau de compreensão de uma mensagem se dá na medida em que ela é resignificada e associada com a vida. Se ela não sofre nenhuma modificação ela é apenas um clichê e se processa na ordem da reprodução. A imagem pode ser engendrada em dois tempos pelo menos: enquanto clichê, ligada à certeza, e enquanto simulação, relacionada à imagem como intermezzo, como barco para adentrar o real e viajá-lo, e neste sentido, torná-lo corpo.

A intenção é se fazer sensível às oportunidades de ancoragem produzidas pelas imagens. Para que se possa pensar sob o ponto de vista das possibilidades da subjetivação, é preciso inicialmente, circunscrever como os desejos são aprisionados e arrastados uniformemente (trajetos subordinados a pontos fixos/endurecimento de segmentaridades/ponto de cruzamento ou ressonância massiva entre os olhares) na criação de certos regimes de verdade que virão a ser a lente por onde passarão a maioria dos olhares.

Quando se pode identificar este tipo de regime territorial endurecido, está-se diante de um "efeito" macropolítico na medida em as sensibilidades podem ser antevistas ou pré-determinadas e a imagem perde a sua vitalidade, não mais sendo transformada pelo espectador, mas, pelo contrário, sendo reproduzida como um xerox.

Um dos aspectos importantes da macropolítica é a sua qualidade de "máquina de ressonância", ou seja, a de homogeneizar os sentidos e correlações. Tal centralização não se opõe aos discursos menos repetitivos que residem no mesmo espaço rizomático, pois, para que as exceções possam ser identificadas devemos ter um parâmetro e um tipo de discursiva insistente. Dentro da macropolítica, que desacelera o potencial de virtualidade da imagem legitimando-a como uma só, existe algo que escapa, transbordando e se alastrando para novos sentidos, justamente em função de combater ou desterritorializar as imposições das segmentaridades solidificadas ou afastar uma espécie de estética linear: micropolítica/quanta.

Assim, o desejo pode ser pensado como arrastado e aprisionado ou resistindo e tornando-se recém dito e pensado. Este espaço, a princípio genuíno, posteriormente pode vir a se tornar um pólo de repetição (as linhas de escape podem tomar força e engendrarem um novo ritmo às marés de produção de sentido) e, por isto, micro e macropolítica estão definitivamente arraigadas, apesar de não serem a mesma e de se articularem, justamente, pela ordem da diferença. Ao passo que a imagem pode gerar ambas as políticas, se pode supor que contenham, em seu interior, forças que propiciem tanto linhas, como a difusão das mesmas e, ainda, trânsitos indeterminados.

Cada píxel da imagem pode ser transformado em um sufocamento ou em transmutação, mas capturado e, a partir disto, tomado, incontestavelmente, pelos agenciamentos de poder que se impõem, devido à sua presença constante entre o autor e o referente.

Com base em Gabriel Tarde (2007), se pode pensar a potência imagética como um "fluxo", uma crença ou desejo que pode se propagar em forma de tradução (sobrecodificação) de uma cópia, mais ou menos desfocada, da imagem apresentada com o intuito de "dar conta", generalizar, encontrar uma suposta essência, criando, assim, uma estrutura baseada em um único eixo e dando a perceber as possibilidades diminutas de mudança de opinião: macropolítica.

Por outro lado, a dita propagação pode não estar inclinada à unificação e permite, então, a produção pela diferença (desterritorialização) caracterizada pela hibridez e por um "controle" menos rígido da produção. E, principalmente, demonstrando maleabilidade no redirecionamento do desejo em relação à imagem e, conseqüentemente, a disposição em ser levado por novas cargas de sentido que, por ventura, poderiam não ter sido percebidas: micropolítica.

$\mathrm{O}$ real pode ser visto tanto como território para a emergência do novo como manancial de repetição de imagens presas a significantes paralisados, ou ainda, como território que existe em função de uma possível imagem que possa tocá-lo, sem bloquear seus fluxos.

Não basta apenas libertar a imagem de seu duplo verdadeiro e correspondente ao real como certeza, mas muní-la de intuição como agenciamento capaz de imaginação e de manutenção da vida (diferente da forma como se apresenta) entendida como proliferação de sentidos.

É preciso também pensar a diferença oriunda da imagem deslocada da mediação da representação. Segundo André Parente (1999, p. 6):

Uma coisa é certa: a auto-referência positiva, desterritorializante, pode ser de dois tipos: uma auto-referência imanente, relacionada à revelação de verdades locais, e a autoreferência transcedental, relacionada à fabulação livre. Tanto uma como a outra liberam a imagem dos modelos e sistemas de verdade.

Portanto, libertar a imagem da verdade é, de alguma forma, libertar o pensamento de seus dogmas de naturalidade, ou, exercício de impermeabilização 
ao erro como se este fosse desvio de seu fluxo "normal", ou deslocá-lo da idéia de agente de reconhecimento, dentro da perspectiva representacional, dando-lhe o emblema de sua positividade no acaso arriscado dos encontros que o forçam a produzir.

Finalmente, através da potência camaleônica da imagem digital, ou de qualquer meio possível, desistir da busca de uma origem que não possa ser atuante no presente. A marca inquieta da transformação continuada da imagem digital indica o desvio do olhar da linearidade tranqüilizante da representação e desorientá-o a ponto de poder estranhar a sonoridade quase imperceptível da repetição.

No horizonte de tal estranhamento e na vontade de desvio da representação é que se pode pensar a transfotografia como exercício político. Assim, a fotografia digital que engendra potência perceptiva aos corpos pode ser concebida como fotografia política, pois não bordeja a interpretação e sim o ultrapassamento do corpo-pensamento na tentativa de mostrá-lo como certo convite à alguma resistência à instituição, à lei, à repetição e, talvez, ao esperado.

Portanto, a manipulação digital de imagens e sua potência inventiva indicam um procedimento de desmultiplicação causal que consiste não em analisar tais práticas como um fato de instituição ou efeito de ideologia, mas desde os múltiplos processos de fazeres simultâneos que concorreram para criar as condições de sua emergência.

Torna-se necessário aquele olhar que leva em consideração a contínua erosão das regras sociais, não por macro-guerras de Estado, mas por práticas referidas como microbianas e que se referem aos sujeitos como terminais de consumo da rede de poderes-saberes. Estes se encontram alocados no social como pontos moleculares a partir dos quais, alguma fissura se alarga, outra é vedada, na interminável e impossível tarefa de estabelecimento do controle social a partir de um centro irradiador. Antes do que uma ampla e reta estrada, um labirinto de muitas entradas, muitos feixes em bifurcação, impulsionados por um modo rizomático de expansão.

O que está em pauta no ato fotográfico processual, que é pós-captação da imagem in loco, é denotar certa resistência na instauração de crise e crítica do atual. A fotografia política convida para maquinação diferentemente da interpretação porque através de sua força ela pode transmitir uma energia capaz de ultrapassar a representação. A manipulação fotográfica revela uma fotografia e, mais ainda, um ente sempre ficcional. Assumir tal condição libera a imagem da verdade e relança a produção sobre o visto em espaço integral e indissociável do visto e dos que vêem.

Rastrear pela imagem pregnante, o exercício oriundo da resistência à forma primeira, da reinvenção do corpo desterritorializado que busca acomodaçãosentido e, para isto, modifica, desfaz, pinta, filtra, recorta e cola inspirado é produção política. Cria-se, então, um modo de agonia da forma inicial da imagem fotográfica ou a metabolização da imagem vai tecendo corpos estranhos e cada modificação vai contagiar a próxima, até que por saturação de diferença o novo afinal é definido.

A referida intervenção contém o passado e o futuro da fotografia e apresenta, a cada click no mouse, atualizações, contrariando, com estilo singular, o adestramento e disciplina na criação de mundos.

Os corpos poderão ser tomados pela tênue alegria que primeiro toma a lente fotográfica de quem dispara e, depois, parte pelo mundo: alguém, finalmente, levanta-se e refaz. Tal é o que pretendemos pensar na presente proposta.

Nietzsche (1995), em seus estudos biológicos relativos ao corpo concebeu a definição da vida como excitação ou como irritação, mas inicialmente, passiva, no sentido que sua matéria é reativa.

No pensamento de Nietzsche e também no de Deleuze, a afirmação do corpo, parte da afirmação do próprio sofrimento e seu ultrapassamento. Majoritariamente, o corpo protege-se da dor por fugas, defesas ou pela passividade. A questão voltada à reversão do corpo na dor é de que a exposição ao sofrimento pode vir a aumentar a potência de ação dos corpos.

Aqui, então, o corpo sai do mero campo reativo e parte para uma linha de fuga inventiva. A resistência, portanto refere-se ao exercício da manutenção da sensibilidade e da abertura às feridas sutis. Para os filósofos a fraqueza está em sentir o menos possível, controlando ao máximo o grau de exposição. Exporse, existencialmente, pela manipulação de imagens seria lidar com o impacto da imagem escolhida para entrar e tecer autoria.

O perigo é o intolerável na captura da própria diferença. Imagem que faz valer a intensidade da procura talvez em um pequeno gesto, em uma parte do corpo, em um suspiro o vislumbrar de um sujeito histórico que possua a marca de contra-fluxo e de práticas conscientes ou não, de seu caráter extemporâneo. Enquadrar aquilo que escapa, mostrar o outro de nós não seria a resistência ao Eu e às pequenas ansiedades narcísicas cheias de culpa e apego? Mergulhar na imagem alheia e, ali, criar um espaço, uma pequena pátria mutante. 
Fazer do visível um estado de tensão interna com o socius e retribuir a opressão da forma de modo a não posicionar-se com ressentimentos que culminam em passividade e queixa. Entretanto, apenas corporificar invenção e sopro fresco de liberação de saúde. Exercitar a coragem e expor-se ao limite da aceitação na aproximação dos tantos inimigos das afirmações de força do corpo. Tal aproximação faz-se necessária na convocação de uma pequena guerra, pois, para que a resistência seja vivida é preciso sentir certo peso do mundo, certa ofensa do fora e certo vislumbre da existência insidiosa do pathos.

Estar à altura do inimigo sem tocar a vitimização que espreita, estar atento, de olhos abertos prontos para disparar a vida. Assim é a fotografia política, ela precisa de provocação, de violência, de pontos de opressão. Para que o click seja disparado ou a manipulação seja criada, o fotógrafo e quem desfaz o click, precisam ser afetados para que desvele seus olhares, para que o encontro possa ser posteriormente mostrado como espaço de "outramento" para que, então, outros desejem ver.

Registrar imagens fotográficas em processo é forma de integrar certas lutas e multiplicar a resistência fazendo-a adentrar em outras retinas e rebrilhar o exercício micropolítico de renovação da face do mundo. Que este mostrar possa ser de forma a não banalizar e que as defesas da diferença possam ser tratadas vigorando o desejo de aproximação. Finalmente, torna-se importante ressaltar que aqui está exposta uma possibilidade de compreensão da imagem digital nos modos de subjetivação contemporâneos e como pesquisadores da Psicologia, temos um convite ao pensamento. A questão que se coloca precisa ser debatida, coletivamente, se abrindo e diferenciando em múltiplos posicionamentos tal e qual a imagem que nos ocupamos.

\section{REFERÊNCIAS}

Deleuze, G. (1991). A dobra: Leibniz e o Barroco. Campinas, SP: Papirus.

Deleuze, G. (1992). O que é filosofia? São Paulo: Ed. 34.

Guattari, F. \& Rolnik, S. (1993). Micropolítica: cartografias do desejo. Petrópolis: Vozes.

Nietzsche, F. (1995). Ecce homo: como alguém se torna o que é. São Paulo: Companhia das Letras.

Parente, A. (1999). O virtual e o hipertextual. Rio de Janeiro: Pazulin.

Proust, M. (1998). O tempo redescoberto. São Paulo: Globo.

Serres, M. (1994). Atlas. Lisboa: Instituto Piaget.

Tarde, G. (2007). Monadologia e Sociologia e outros ensaios (P. Neves, Trad.). Em E. V. Vargas (Ed.), Gabriel Tarde Monadologia e Sociologia e outros ensaios. São Paulo: Cosac Naify.
Endereço para correspondência:
Patrícia Kirst. R. Aurélio Bittencourt,150/302, Bairro: Rio Branco, CEP: 90430-080, Porto Alegre-RS, Brasil. E-mail: pgomes.voy@terra.com.br.
Recebido em 24/09/2008 Aceito em 16/12/2009 